\section{Basic and Applied Ecology}

www.elsevier.de/baae

\title{
Can root-feeders alter the composition of AMF communities? Experimental evidence from the dune grass Ammophila arenaria
}

\author{
Susana Rodríguez-Echeverría ${ }^{\mathrm{a}, *}$, Eduardo de la Peña ${ }^{\mathrm{a}, \mathrm{b}, \mathrm{c}}$, Maurice Moens ${ }^{\mathrm{b}, \mathrm{d}}$, \\ Helena Freitas ${ }^{\mathrm{a}}$, Wim H. van der Putten ${ }^{\mathrm{e}, \mathrm{f}}$ \\ ${ }^{a}$ Centre for Functional Ecology, Department of Botany, University of Coimbra, PT-3000 Coimbra, Portugal \\ ${ }^{\mathrm{b}}$ Institute for Agriculture and Fisheries Research (ILVO), Burg. Van Gansberghelaan 96, 9820 Merelbeke, Belgium \\ ${ }^{\mathrm{c}}$ Terrestrial Ecology Unit, Department of Biology, Faculty of Sciences, Ghent University, K.L. Ledeganckstraat 35 , \\ 9000 Ghent, Belgium \\ ${ }^{\mathrm{d} D e p a r t m e n t}$ of Agrozoology, Faculty of Bioscience Engineering, Ghent University, Coupure 653, 9000 Ghent, Belgium \\ ${ }^{\mathrm{e}}$ Multitrophic Interactions Department, Netherlands Institute of Ecology (NIOO-KNAW), Boterhoeksestraat, \\ GA 6666 Heteren, The Netherlands \\ ${ }^{\mathrm{f}}$ Nematology Department, Wageningen University, Binnenhaven 5, 6709 PD, Wageningen, The Netherlands
}

Received 20 July 2007; accepted 28 January 2008

\begin{abstract}
Root herbivores and plant mutualists, such as arbuscular mycorrhizal fungi (AMF), have a significant effect on the structure and dynamic of plant communities. Nevertheless, the interactions between the two groups of organisms in natural ecosystems are far from understood. We carried out an inoculation experiment to examine the effect of two root herbivores, Pratylenchus penetrans and P. dunensis (Nematoda), on the composition of the AMF communities associated with two populations of the dune grass Ammophila arenaria. The outcome of the interaction in terms of plant and nematode performance was also analyzed. The total percentage of AMF colonization was not affected by the presence of root-feeders, but they did alter the composition of the AMF communities inside the roots. These changes were dependent on the root-feeder species and the original AMF community: the most severe alterations were observed in the mycorrhizal plants from Wales attacked by P. penetrans. Plant growth was impaired in plants from Wales inoculated with AMF and $P$. dunensis, which suggests a highly species-specific synergistic interaction with negative consequences for the plant. Root infection by the nematodes was reduced in all mycorrhizal plants when compared to non-mycorrhizal plants. However, a significant reduction of the final number of nematodes was observed only in the mycorrhizal plants from one population.
\end{abstract}

(C) 2008 Gesellschaft für Ökologie. Published by Elsevier GmbH. All rights reserved.

\section{Zusammenfassung}

Wurzelfresser und Pflanzenmutualisten, wie arbuskuläre Mykorrhizapilze (AMF), haben einen signifikanten Effekt auf die Struktur und Dynamik von Pflanzengesellschaften. Dennoch sind die Interaktionen zwischen den beiden Gruppen von Organismen in natürlichen Ökosystemen weit von einem Verständnis entfernt. Wir führten ein Inokulationsexperiment durch, um die Effekte von zwei Wurzelherbivoren, Pratylenchus penetrans und P. dunensis

\footnotetext{
${ }^{*}$ Corresponding author. Tel.: + 351239855244 ; fax: + 351239855211.

E-mail address: susanare@ci.uc.pt (S. Rodríguez-Echeverría).
} 
(Nematoda) auf die Zusammensetzung von AMF-Gesellschaften zu untersuchen, die mit zwei Populationen des Dünengrases Ammophila arenaria assoziiert waren. Das Ergebnis der Interaktionen in Bezug auf die Pflanzen- und Nematodenperformanz wurde ebenfalls analysiert. Die gesamte prozentuale Kolonisation durch AMF wurde durch die Anwesenheit der Wurzelfresser nicht beeinflusst. Sie veränderten jedoch die Zusammensetzung der AMFGesellschaften in den Wurzeln. Diese Änderungen hingen vom Wurzelfresser und der ursprünglichen AMFGesellschaft ab: die heftigsten Veränderungen wurden bei Mykorrhizapflanzen aus Wales festgestellt, die von $P$. penetrans befallen wurden. Das Pflanzenwachstum war bei Pflanzen aus Wales verringert, die mit AMF und $P$. dunensis inokuliert waren. Dies lässt eine sehr artspezifische synergistische Interaktion mit negativen Konsequenzen für die Pflanzen vermuten. Der Nematodenbefall war bei allen Pflanzen mit Mykorrhiza im Vergleich zu Pflanzen ohne Mykorrhiza reduziert. Eine signifikante Reduktion der endgültigen Anzahl der Nematoden wurde jedoch nur bei Pflanzen mit Mykorrhiza aus einer Population beobachtet.

(C) 2008 Gesellschaft für Ökologie. Published by Elsevier GmbH. All rights reserved.

Keywords: Bottom-up control; DGGE; Dunes; Functional diversity; Pratylenchus spp.; Mutualism; Belowground-herbivory; Plant parasitic nematodes

\section{Introduction}

In the last 10 years, there has been an increased research effort to unravel the belowground complexity and to link it with aboveground ecology (Wardle et al., 2004). The interactions between plant roots and soil organisms have a significant effect on the structure and dynamic of both belowground and aboveground communities (Bever, Westover, \& Antonovics, 1997; De Deyn et al., 2003; Van der Putten, Vet, Harvey, \& Wackers, 2001; Wardle et al., 2004). Root-feeders, pathogens and plant mutualists coexist in the rhizosphere of plants and their interactions can lead to changes in the belowground community, which in turn affect plant performance and community structure (Bezemer et al., 2005; Van der Putten, Van Dijk, \& Peters, 1993). Nevertheless, these belowground interactions and their ecological relevance in natural systems are far from being fully understood (Borowicz, 2006).

The role of root-feeders in the decline of Ammophila arenaria in coastal sand dunes is one of the best documented cases illustrating how soil biota affect aboveground processes in natural systems (Van der Putten, Maas, Van Gulik, \& Brinkman, 1990). This is a good system for ecological studies on belowground interactions because of the large amount of data available on plant-soil interactions and soil diversity (Costa, Davies, Bardgett, \& Kerry, 2003; de Rooij-van der Goes, 1995; Kowalchuk, Gerards, \& Woldendorp, 1997; Rodriguez-Echeverria \& Freitas, 2006; Van der Putten et al., 1990), and because the sandy soil is a relatively easy substrate for soil ecological studies. Initially, it was thought that root-feeding nematodes could play a significant role as belowground grazers in coastal sand dunes (Van der Putten et al., 1990). However, nematode abundance in the foredunes is usually low and subsequent work showed that rootfeeding nematodes are strongly controlled in this soil
(De Rooij-Van der Goes, 1995). Recent studies have demonstrated that a wide array of nematode control mechanisms can be found in the foredunes. Different root-feeding nematode species are ruled out by bottomup processes (Van der Stoel \& van der Putten, 2006), horizontal competition (Brinkman, Duyts, \& van der Putten, 2005), plant mutualists (de la Peña, RodriguezEcheverria, van der Putten, Freitas, \& Moens, 2006; Greipsson \& El-Mayas, 2002; Hol, de la Peña, Moens, \& Cook, 2007; Little \& Maun, 1996) and/or natural enemies (Piśkiewicz, Duyts, Berg, Costa, \& van der Putten, 2007). However, little is known about the effect of root-feeding nematodes on other rhizosphere organisms in natural systems. Among these, arbuscular mycorrhizal fungi (AMF) are the most likely to be affected by root herbivores because of the close relationship between them and plant roots.

AMF are ubiquitous plant mutualists which represent a large fraction of the fungal biomass of the rhizosphere. AMF are particularly beneficial for plants in sand dunes because they facilitate nutrient uptake in these lowfertility soils and play a key role in sand stabilization (Koske \& Gemma, 1997). AMF can also act as mediators between plants and above and belowground herbivores (Brown \& Gange, 2002). The outcome of this interaction depends mainly on the life history traits of the herbivore, the physiological status of the host plant and the composition of the AMF community ( $\mathrm{Hol} \&$ Cook, 2005). Different AMF species can have different effects on plant growth and chemistry and, therefore, on herbivore performance (Gange, Brown, \& Aplin, 2005). In addition, the effect of mixtures of AMF species on herbivore performance can differ from the effects of single AMF (Gange, 2001). In terms of the consequences of the interaction for the AMF community, aboveground herbivory can reduce the extent of root colonization by the fungal mutualists (Gange, Bower, \& Brown, 2002), although this effect seems to be 
species-specific (Klironomos, McCune, \& Moutoglis, 2004). For belowground herbivores, de la Peña et al. (2006) showed that the root-feeding nematode Pratylenchus penetrans did not affect root colonization by AMF. Nevertheless, whether belowground herbivores also have differential effects on different fungal species is not clear yet (Borowicz, 2006). The composition of the AMF communities in natural systems is relevant for ecosystem dynamics because of the functional and physiological differences among AMF (Maherali \& Klironomos, 2007). In the case of $A$. arenaria, distinctive AMF communities have been found in association with the plant roots in either different locations or dune succession stages (Blaszkowski, 1994; Kowalchuk, De Souza, \& Van Veen, 2002; Rodriguez-Echeverria, Hol, Freitas, Eason, \& Cook, 2007). Kowalchuk et al. (2002) also showed that the AMF communities associated with $A$. arenaria in healthy stands were different from those of degenerating plants, suggesting a link between plant performance, changes in the AMF community and changes in the populations of other rhizosphere organisms. When $A$. arenaria degenerates, it is replaced by later successional plant species (Van der Putten et al., 1993). Therefore, the causes that lead to changes in the AMF communities can have important consequences for the ecosystem.

In the present study, we tested the hypothesis that root-feeders can change the AMF community structure in the roots of the attacked plant. In order to test this hypothesis, we designed an experiment using two genetically different populations of $A$. arenaria (Rodriguez-Echeverria, Freitas, \& van der Putten in press) inoculated with their native AMF communities, and two species of root-feeding nematodes, $P$. penetrans and $P$. dunensis, which occur frequently in the rhizosphere of $A$. arenaria (de la Peña, Karssen, \& Moens, 2007). We discuss our results in relation to the dynamics of root herbivores and AMF communities in natural ecosystems and the aboveground consequences of this interaction.

\section{Materials and methods}

\section{Collection and preparation of plants, AMF and nematodes}

Seeds of $A$. arenaria were collected in Ynyslas (Wales, UK) and Het Zwin Nature Reserve (Knokke, Belgium). Seeds were germinated in a glasshouse with a $16 \mathrm{~h} / 8 \mathrm{~h}$ light/dark regime and $25^{\circ} \mathrm{C} / 16^{\circ} \mathrm{C}$ day/night temperature on 2-mm-diameter glass beads with demineralized water. Two-week-old seedlings with 2 -cm-tall shoots were used in the bioassays.

Soil was collected from the rhizosphere of four different $A$. arenaria plants in Het Zwin and Ynyslas to set up separate trap cultures of the AMF community with corn (Zea mays L.) as host plant. Spores were extracted from the trap cultures by wet sieving and inspected under a stereoscopic microscope (Leica MZ 8). Most spores from both sites belonged to Glomus spp. Healthy spores of both cultures were collected, washed and re-suspended in autoclaved distilled water to obtain suspensions with a final concentration of 100 spores $\mathrm{ml}^{-1}$ for each origin.

Pratylenchus dunensis was isolated originally from $A$. arenaria stands in Oostvoorne, the Netherlands, and $P$. penetrans from Zea mays in Zandhoven, Belgium. Both populations were multiplied on $A$. arenaria plants in sterilized soil for 9 months before the experiment was set up. To obtain nematodes for the inoculation experiments, soil and plant roots from cultures were sieved through a $0.5-\mathrm{cm}$ mesh and the obtained roots were chopped in 1-cm fragments and placed in a funnel over a cotton filter. The funnels were placed in a mist chamber at $20^{\circ} \mathrm{C}$ and tapped off every day during 1 week to collect nematodes in water. Nematode identity was checked prior to inoculation by morphology and sequencing of the ITS region (de la Peña et al., 2007).

\section{Experimental set-up}

For each of the two A. arenaria plant populations, we set up six treatments with five replicated pots per treatment: non-inoculated control $(\mathrm{C})$, inoculation with $\operatorname{AMF}(\mathrm{F})$, inoculation with $P$. penetrans $(\mathrm{Pp})$, inoculation with $P$. dunensis $(\mathrm{Pd})$, inoculation with $\mathrm{AMF}$ and $P$. penetrans (F-Pp) and inoculation with AMF and $P$. dunensis (F-Pd). Four seedlings of $A$. arenaria were planted in 1.5-1 pots filled with $1800 \mathrm{~g}$ of autoclaved dune sand. In the inoculation treatments, each pot received 700 nematodes (mobile stages) and/or 550 AMF spores. Nematodes and AMF were inoculated at the same time to mimic natural conditions and give nematodes and AMF the same chance to colonize plant roots. Pots were covered with tin foil to prevent desiccation and watered every second day to keep the moisture content at $5-10 \%$ based on pot weight. Every 2 weeks all pots were watered with $120 \mathrm{ml}$ half-strength modified (P-free) Hoagland's nutrient solution. The pots were placed in the greenhouse in a full randomized design and repositioned every 2 weeks, after each fertilizer application. The experiment was conducted for 14 weeks, from June 2004 until September 2004.

\section{Harvest, data collection and statistical analyses}

After harvest, fresh root weights were obtained and a portion of each root was subsequently cut, weighed and stained using acid fuchsine for nematode and AMF assessment (Baker \& Gowen, 1996). After taking the 
root fraction for assessing colonization, the remaining plant material was dried at $72{ }^{\circ} \mathrm{C}$ for $48 \mathrm{~h}$ to determine plant biomass. Total root biomass was estimated including the root fraction taken for assessing root colonization. Using a compound microscope, root infection by AMF and nematodes was estimated as the percentage of $1-\mathrm{cm}$ root fragments containing structures of these organisms. Nematodes were counted in each root fragment to estimate the total number of nematodes per gram of root. Nematodes were also extracted from soil by zonal centrifugation following Hendrickx (1995). Nematodes in any developmental stage, eggs included, were counted. The total number of nematodes per pot was calculated by adding up the number of nematodes in both roots and soil.

A three-way ANOVA was used to test if the effect of plant origin, AMF and nematode species on herbivore performance and plant growth were independent of local conditions and nematode identity. Differences in AMF infection were examined using a two-way ANOVA with plant origin and nematode as fixed factors. Tukey's HSD post hoc tests were used to analyze the statistical differences between groups. Prior to analysis, data were checked for normality and homogeneity of variances. The biomass data were square root transformed to meet ANOVA assumptions. All statistical analyses were performed using SPSS 14.0.

At the end of the experiment, the AMF communities associated with $A$. arenaria in each treatment were analyzed by PCR-DGGE. DGGE (Denaturing Gradient Gel Electrophoresis) separates DNA fragments of similar size but with different base sequences by exploiting the melting behavior of DNA. Put simply, DNA with different base sequences (i.e. different $\mathrm{G}+\mathrm{C}$ content) melt at different positions in a polyacrylamide gel containing a linear gradient of denaturants (DGGE). The DNA fragments are amplified from environmental samples using specific primers for the studied fungal or bacterial group. Therefore, as with many molecular techniques, the information obtained by PCR-DGGE is limited by the variability of the selected DNA region and the availability of specific primers. Nevertheless, it is a powerful technique to observe the composition of fungal or bacterial communities, which otherwise are impossible to analyze (Anderson \& Cairney, 2004).

Samples containing approximately twenty, $1-\mathrm{cm}$ root pieces from each pot were used for DNA extraction and subsequent molecular analysis. Total DNA was extracted using the Nucleon Phytopure Plant DNA extraction kit (Amersham Biosciences, Freiburg, Germany) following the manufacturer's protocol. A nestedPCR was used to selectively amplify the fungal LSU rDNA sequences from the extracts using the primers LR1 and FLR2 (Gollotte, van Tuinen, \& Atkinson, 2004) in the first reaction and FLR3-GC (FLR3 plus a GC clamp at the $5^{\prime}$ end) and FLR4 for the second reaction. FLR3 and FLR4 were described by Gollotte et al. (2004) as specific for Glomeromycota fungi. All reactions were carried out in a GeneAmp PCR 9700 system (Perkin-Elmer, CA, USA).

The products from the second PCR were examined by standard $1 \%(\mathrm{w} / \mathrm{v})$ agarose gel electrophoresis with ethidium bromide staining, to confirm product integrity and estimate yield. One band of $380 \mathrm{bp}$ was obtained in all samples. Approximately $0.4 \mu \mathrm{g}$ of DNA from each sample was used for DGGE analysis. Gels contained $8 \%(\mathrm{w} / \mathrm{v})$ polyacrylamide (37:1 acrylamide/bis-acrylamide) and $1 \times$ TAE. The linear gradient used was from $27 \%$ to $43 \%$ denaturant, where $100 \%$ denaturing is defined as containing $7 \mathrm{M}$ urea and $40 \%(\mathrm{v} / \mathrm{v})$ formamide (Muyzer \& Smalla, 1998). Electrophoresis was run at $20 \mathrm{~V}$ for $15 \mathrm{~min}$, and afterwards at $200 \mathrm{~V}$ for $330 \mathrm{~min}$ with a constant temperature of $60^{\circ} \mathrm{C}$ in a DGGE-2401 system from CBS Scientific (CA, USA). Afterwards, gels were stained with ethidium bromide and visualized in a UV transilluminator. Digital images were captured using a Vilber Loumat system and analyzed with GelCompar II version 4.0 (Applied Maths, Kortrijk, Belgium). UPGMA dendrograms were constructed using the Pearson correlation coefficient to calculate the similarities between samples. The result was statistically tested using one-way ANOVA on the values from the similarity matrix.

\section{Results}

\section{Effect of AMF on the root-feeders}

Root infection by nematodes was reduced from values of $70 \%$ in non-mycorrhizal plants to about $50 \%$ in mycorrhizal plants (Fig. 1A). The three-way ANOVA showed a significant effect of the presence of AMF on root colonization by nematodes $\left(F_{1,32}=41.41\right.$, $P<0.001)$ (Table 1, Fig. 1B). The two other factors considered in the analysis, origin of plant/AMF and identity of the herbivore species, did not have any significant effect on this variable (Table 1).

The final number of nematodes in all treatments from Belgium was about 5600 with the exception of $P$. penetrans in mycorrhizal plants, which had a final number of 4000 individuals (Fig. 2A). In non-mycorrhizal plants from Wales, there were 6600 and 4900 nematodes of $P$. penetrans and $P$. dunensis, respectively. These numbers were reduced to about 2300 in mycorrhizal plants (Fig. 2A). The three-way ANOVA showed a significant effect of the presence of AMF $\left(F_{1,32}=15.33, \quad P<0.001\right)$, the origin of plant/AMF $\left(F_{1,32}=8.69, P<0.01\right)$ and an interaction between the two factors $\left(F_{1,32}=5.07, P<0.05\right)$ on the final number of nematodes (Table 1). The Tukey HSD post hoc test 


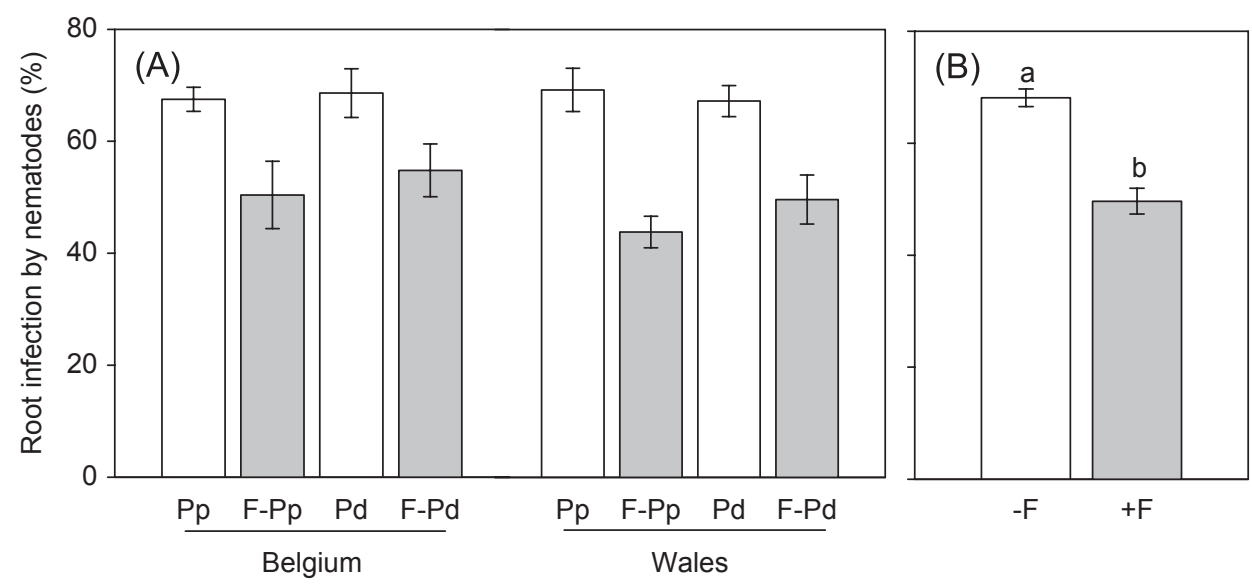

Fig. 1. (A) Root infection (mean \pm S.E.) by $P$. penetrans and $P$. dunensis in each experimental treatment $(N=5)$. Pp: inoculation with $P$. penetrans, $\mathrm{Pd}$ : inoculation with $P$. dunensis; F-Pp: inoculation with AMF and $P$. penetrans; F-Pd: inoculation with AMF and $P$. dunensis. (B) Pooled data for root infection by both nematodes in non-mycorrhizal plants $(-F)$ and mycorrhizal plants $(+F)$ $(N=20)$. Different letters mean significant differences (Tukey HSD post hoc tests after three-way ANOVA).

Table 1. Results of the three-way ANOVA for treatment effects on nematode performance measured as percentage of root infection by nematodes and total number of nematodes. Significant $P$ values are in bold

\begin{tabular}{lrrrrrr}
\hline & d.f. & \multicolumn{2}{c}{ Root infection } & & \multicolumn{2}{c}{ Total number } \\
\cline { 3 - 4 } & & \multicolumn{2}{c}{$F$} & & & \multicolumn{2}{c}{$P$} \\
\hline Origin & 1 & 1.00 & 0.324 & & 8.69 & $\mathbf{0 . 0 0 6}$ \\
AMF & 1 & 41.41 & $<\mathbf{0 . 0 0 1}$ & & 15.33 & $<\mathbf{0 . 0 0 1}$ \\
Nematode & 1 & 0.66 & 0.424 & & 0.03 & 0.865 \\
Origin $\times$ AMF & 1 & 1.11 & 0.300 & & 5.07 & $\mathbf{0 . 0 3 1}$ \\
Origin $\times$ nematode & 1 & 0.02 & 0.883 & & 0.44 & 0.513 \\
AMF $\times$ nematode & 1 & 0.93 & 0.341 & & 3.31 & 0.078 \\
Origin $\times$ AMF $\times$ & 1 & 0.15 & 0.698 & & 0.49 & 0.489 \\
nematode & & & & & \\
Error & 32 & 0.03 & & & 0.008 & \\
\hline
\end{tabular}

on the interaction AMF $\times$ origin found a significant reduction of the final number of nematodes in the mycorrhizal plants from Wales (Fig. 2B).

\section{Effect of the root-feeders on AMF}

Root colonization by AMF was about $50 \%$ in plants from Belgium and $40 \%$ in plants from Wales (Fig. 3). The two-way ANOVA showed a significant effect of plant/ AMF origin on mycorrhizal infection $\left(F_{1,24}=5.08\right.$, $P<0.05)$ but no effect of the presence of nematodes on the percentage of root colonized by AMF (Fig. 3, Table 2).

In spite of this, the PCR-DGGE showed that rootfeeders altered the composition of the AMF communities colonizing the roots of $A$. arenaria (Fig. 4A and B). The variation in the structure of the AMF communities differed in both plant/AMF origins. The overall similarity of samples was higher in plants from
Belgium than from Wales. Even so, the analysis of the PCR-DGGE data separated the three treatments: mycorrhizal plants, mycorrhizal plants inoculated with $P$. penetrans and mycorrhizal plants inoculated with $P$. dunensis (Fig. 4A). The three groups were statistically different (one-way ANOVA, $P<0.001$ ). In the case of plants from Wales, the AMF community structure of plants inoculated with $P$. penetrans was significantly different $(P<0.001)$ than that of the other treatments (Fig. 4B). Only one PCR product could be obtained from roots inoculated with AMF and $P$. dunensis and this sample grouped with the mycorrhizal plants not inoculated with nematodes (Fig. 4B).

\section{Plant growth}

Plant biomass ranged between 0.22 and $0.40 \mathrm{~g}$ per plant for Belgium and between 0.21 and $0.46 \mathrm{~g}$ for Wales (Fig. 5). Because the statistical analysis of the data for root and shoot biomass produced the same results as those for total biomass, only the latter are presented. The three-way ANOVA showed a significant effect of the inoculation with nematodes $\left(F_{2,48}=3.78, \quad P<0.05\right)$ and of the interaction between the three factors (nematode, plant/ AMF origin and AMF inoculation, $F_{2,48}=4.65, P<0.05$ ) on plant biomass (Table 3). The post hoc comparisons with Tukey HSD test revealed that the simultaneous inoculation with AMF and $P$. dunensis lead to a significant reduction of plant growth in Wales (Fig. 5).

\section{Discussion}

The presence of AMF always reduced root infection by both nematode species, a result that agrees with 

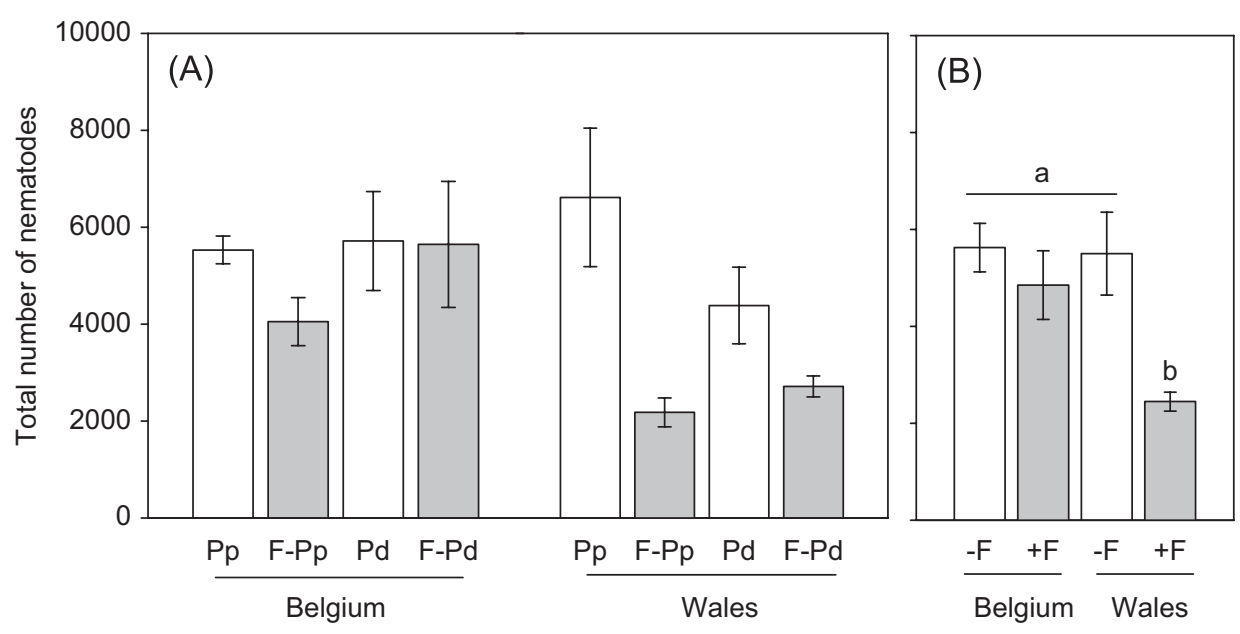

Fig. 2. (A) Total number (mean \pm S.E.) of $P$. penetrans and $P$. dunensis in each experimental treatment $(N=5)$. Treatments as in Fig. 1A. (B) Pooled data for total number of both nematode species for non-mycorrhizal plants $(-F)$ and mycorrhizal plants $(+F)$ from Belgium and Wales $(N=10)$. Different letters mean significant differences (Tukey HSD post hoc tests after three-way ANOVA).
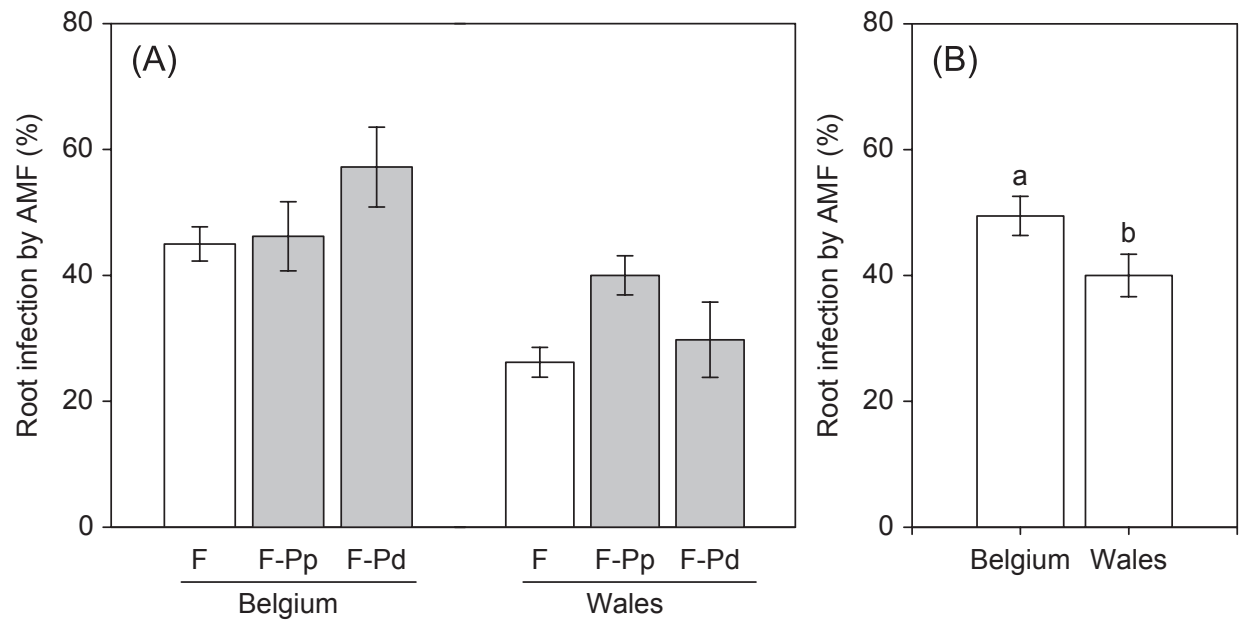

Fig. 3. (A) Root colonization (mean \pm S.E.) by AMF in each experimental treatment $(N=5)$. F: inoculation with a natural mixed culture of AMF; F-Pp and F-Pd as in Fig. 1A. (B) Pooled data for AMF colonization for each origin $(N=20)$. Different letters mean significant differences (Tukey HSD post hoc tests after two-way ANOVA).

Table 2. Results of the two-way ANOVA for treatment effects on root infection by AMF. Significant $P$ values are in bold

\begin{tabular}{lccl}
\hline & d.f. & $F$ & $P$ \\
\hline Origin & 1 & 5.08 & $\mathbf{0 . 0 3 4}$ \\
Nematode & 2 & 2.00 & 0.158 \\
Origin $\times$ nematode & 2 & 2.80 & 0.081 \\
Error & 24 & 0.01 & \\
\hline
\end{tabular}

previous data for $P$. penetrans (de la Peña et al., 2006). Nevertheless, the multiplication of the two nematode species was differently affected by AMF. One of the AMF communities only suppressed the generalist $P$. penetrans while the AMF from Wales impaired the reproduction of both root-feeding nematodes. Direct competition for space might be responsible for the suppression of root infection by nematodes (de la Peña et al., 2006; Roncadori, 1997). The suppression of nematode reproduction, however, might also depend on other mechanisms such as local changes in root biochemistry of mycorrhizal plants (Smith, 1987), which could change with the specific composition of the AMF community. The fact that both root-feeders declined significantly only with AMF from Wales suggests that nematode reproduction suppression depends on the AMF community and also on nematode sensitivity. This result agrees with the species-specific effect observed in studies done with single AMF species and herbivorous insects (Gange, 2001; Gange et al., 2005).

Experimental evidence for the role of AMF as a mediator of root-herbivore interactions in natural and 
A

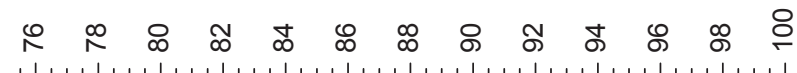
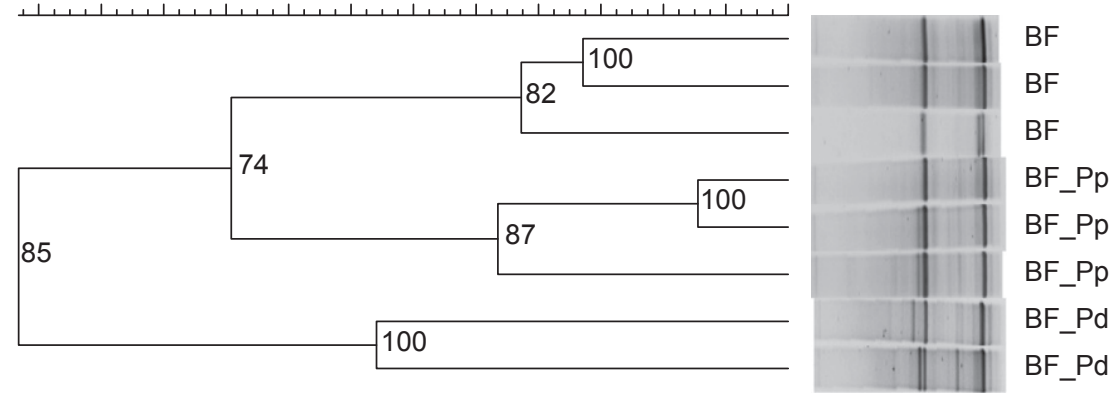

B
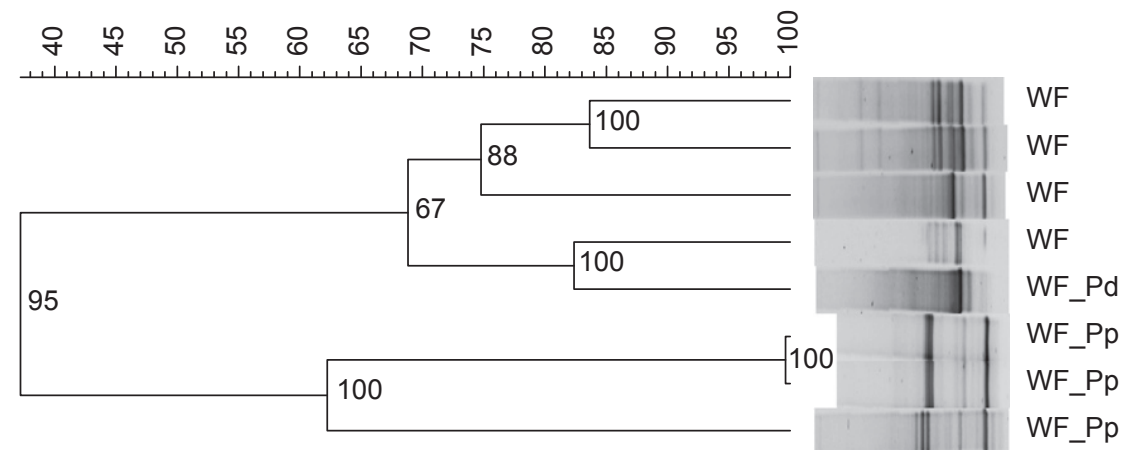

Fig. 4. UPGMA dendrograms for the DGGE profiles of the AMF communities in mycorrhizal plants from (A) Belgium and (B) Wales using the Pearson correlation coefficient. The scale shows similarity values. Cophenetic values are also shown in the nodes. Labels are B: plants from Belgium; W: plants from Wales; F: mycorrhizal plants without inoculation with nematodes; F-Pp and F$\mathrm{Pd}$ as in Fig. 1A.

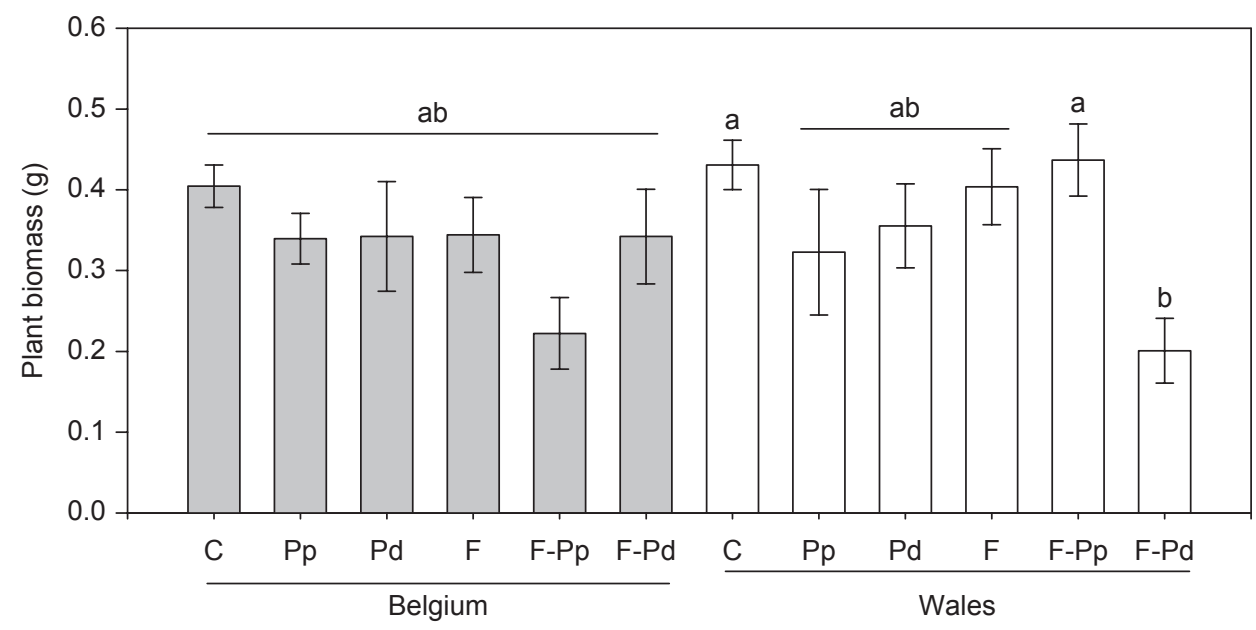

Fig. 5. Biomass (g, mean \pm S.E.) of $A$. arenaria plants from Belgium and Wales $(N=5)$. C: no inoculation, Pp: inoculation with $P$. penetrans, $\mathrm{Pd}$ : inoculation with $P$. dunensis; F: inoculation with a natural mixed culture of AMF; F-Pp: inoculation with AMF and P. penetrans; F-Pd: F-Pp: inoculation with AMF and P. dunensis. Different letters mean significant differences (Tukey HSD post hoc tests after three-way ANOVA).

agricultural systems has been shown in previous studies (Borowicz, 2001; Hol \& Cook, 2005). In contrast, the effect of root-feeders in the composition of AMF colonizing the roots has hardly been addressed before.
Our results show that root-herbivores can alter the AMF community associated with a plant, even if the total percentage of root colonization by AMF is not affected. Some AMF species are known to be more 
Table 3. Results of the three-way ANOVA for treatment effects on plant biomass. Significant $P$ values are in bold

\begin{tabular}{lcll}
\hline & d.f. & $F$ & $P$ \\
\hline Origin & 1 & 0.59 & 0.446 \\
AMF & 1 & 2.54 & 0.117 \\
Nematode & 2 & 3.78 & $\mathbf{0 . 0 3 0}$ \\
Origin $\times$ AMF & 1 & 0.46 & 0.502 \\
Origin $\times$ nematode & 2 & 2.90 & 0.065 \\
AMF $\times$ nematode & 2 & 0.60 & 0.553 \\
Origin $\times$ AMF $\times$ nematode & 2 & 4.65 & $\mathbf{0 . 0 1 4}$ \\
Error & 48 & 0.01 & \\
\hline
\end{tabular}

sensitive to herbivory than others (Klironomos et al., 2004). Therefore, the differential detrimental effect of herbivores in some AMF species could benefit others in terms of root colonization. Interestingly, the results were different for the two AMF communities tested. In the case of plants and AMF from Belgium, the three treatments - mycorrhizal plants without nematodes, mycorrhizal plants with $P$. penetrans and mycorrhizal plants with $P$. dunensis - resulted in three separate groups of AMF communities (Fig. 4A). P. dunensis had a bigger impact on the AMF community obtained from Belgium than $P$. penetrans. In contrast, the AMF community from Wales was more sensitive to the presence of $P$. penetrans (Fig. 4B). This root-feeder was responsible for major alterations in the structure of the fungal community associated with $A$. arenaria. The differential effect of the root-feeders in both plant/AMF origins highlights the complexity of the belowground interactions in natural systems.

The herbivore densities used in our experiments did not result in a reduction of plant growth and the presence of AMF did not increase plant biomass. However, the combination of AMF and P. dunensis in plants from Wales caused a significant reduction of plant biomass. AMF can become parasitic to plants (Johnson, Graham, \& Smith, 1997) and exacerbate the detrimental effect of foliar herbivory (Gange et al., 2002). To our knowledge, it has not previously been shown that AMF can have negative synergistic interactions with root-feeding nematodes. This effect depends on the particular combination of plant, AMF and nematode species. Environmental conditions might also affect this result because previous studies did not detect the detrimental effect of inoculating AMF and nematodes together (de la Peña et al., 2006). It is noteworthy that plant biomass was reduced in the cases where the structure of the AMF communities was less affected by the root-feeder. This opens the question whether the changes in the AMF community happened because of a direct effect of the root-feeder on the fungal species or through physiological changes in the plant caused by the herbivores.

In the field, different AMF communities and nematode species have been found in early and late successional stages of $A$. arenaria (Kowalchuk et al., 2002; Wall, Skene, \& Neilson, 2002). The differential effect of AMF on both Pratylenchus species is likely to affect competition between root-feeding nematodes, which is one of the mechanisms controlling the relative abundance of nematodes in the rhizosphere of $A$. arenaria (Brinkman et al., 2005). However, the presence of different nematode species might also modify the structure of the AMF community leading to further changes for the plant, and subsequently influencing other herbivores. If our results are to be extrapolated to the field, it seems clear that these interactions between root herbivores and AMF could drive the belowground succession of both organisms and, ultimately, affect the composition of plant communities.

\section{Acknowledgments}

This study is part of the EcoTrain project (HPRN-CT 2002 00210) funded by the European Union. The authors thank Kris Struyf, curator of Het Zwin Nature Reserve, for allowing collection of samples. Eduardo de la Peña is a post doctoral fellow of the Flemish Science Foundation (FWO).

\section{References}

Anderson, I. C., \& Cairney, J. W. G. (2004). Diversity and ecology of soil fungal communities: Increased understanding through the application of molecular techniques. Environmental Microbiology, 6, 769-779.

Baker, T. J., \& Gowen, S. R. (1996). Staining nematodes and arbuscular mycorrhizae in the same root sample. Fundamental and Applied Nematology, 19, 607-608.

Bever, J. D., Westover, K. M., \& Antonovics, J. (1997). Incorporating the soil community into plant population dynamics: The utility of the feedback approach. Journal of Ecology, 85, 561-573.

Bezemer, T. M., De Deyn, G. B., Bossinga, T. M., van Dam, N. M., Harvey, J. A., \& van der Putten, W. H. (2005). Soil community composition drives aboveground plant-herbivore-parasitoid interactions. Ecology Letters, 8, 652-661.

Blaszkowski, J. (1994). Arbuscular fungi and mycorrhizae (Glomales) of the Hel Peninsula, Poland. Mycorrhiza, 5, 71-88.

Borowicz, V. A. (2001). Do arbuscular mycorrhizal fungi alter plant-pathogen relations? Ecology, 82, 3057-3068.

Borowicz, V. A. (2006). When enemies attack do plants get by with a little help from their friends? New Phytologist, 169, 644-646.

Brinkman, E. P., Duyts, H., \& van der Putten, W. H. (2005). Consequences of variation in species diversity in a 
community of root-feeding herbivores for nematode dynamics and host plant biomass. Oikos, 110, 417-427.

Brown, V. K., \& Gange, A. C. (2002). Tritrophic below- and above-ground interactions in succession. In T. Tscharntke (Ed.), Multitrophic level interactions (pp. 148-173). Cambridge: Cambridge University Press.

Costa, S., Davies, K.G., Bardgett, R.D., \& Kerry, B.R. (2003). Fungal antagonists to nematodes parasitic on Ammophila arenaria. Paper presented at the British Ecological Society annual symposium 2003: Biological diversity and function in soils. Lancaster, UK.

De Deyn, G. B., Raaijmakers, C. E., Zoomer, H. R., Berg, M. P., De Ruiter, P., Verhoef, H. A., et al. (2003). Soil invertebrate fauna enhances grassland succession and diversity. Nature, 422, 711-713.

de la Peña, E., Karssen, G., \& Moens, M. (2007). Diversity and distribution of root-lesion nematodes (Pratytlenchus spp.) associated with Ammophila arenaria L. (Link) in coastal dunes of Western Europe. Nematology, 9, 881-901.

de la Peña, E., Rodriguez-Echeverria, S., van der Putten, W. H., Freitas, H., \& Moens, M. (2006). Mycorrhizal fungi control migratory endoparasitic nematodes in Ammophila arenaria. New Phytologist, 169, 829-840.

de Rooij-van der Goes, P. C. E. M. (1995). The role of plantparasitic nematodes and soil-borne fungi in the decline of Ammophila arenaria (L) Link. New Phytologist, 129, 661-669.

Gange, A. C. (2001). Species-specific responses of a root- and shoot-feeding insect to arbuscular mycorrhizal colonization of its host plant. New Phytologist, 150, 611-618.

Gange, A. C., Bower, E., \& Brown, V. K. (2002). Differential effects of insect herbivory on arbuscular mycorrhizal colonization. Oecologia, 131, 103-112.

Gange, A. C., Brown, V. K., \& Aplin, D. M. (2005). Ecological specificity of arbuscular mycorrhizae: Evidence from foliarand seed-feeding insects. Ecology, 86, 603-611.

Gollotte, A., van Tuinen, D., \& Atkinson, D. (2004). Diversity of arbuscular mycorrhizal fungi colonising roots of the grass species Agrostis capillaris and Lolium perenne in a field experiment. Mycorrhiza, 14, 111-117.

Greipsson, S., \& El-Mayas, H. (2002). Synergistic effect of soil pathogenic fungi and nematodes reducing bioprotection of arbuscular mycorrhizal fungi on the grass Leymus arenarius. Biocontrol, 47, 715-727.

Hendrickx, G. A. (1995). Automatic apparatus for extracting free-living nematodes stages from soil. Nematologica, 41, 30.

Hol, W. H. G., \& Cook, R. (2005). An overview of arbuscular mycorrhizal fungi-nematode interactions. Basic and Applied Ecology, 6, 489-503.

Hol, W. H. G., de la Peña, E., Moens, M., \& Cook, R. (2007). Interactions between a fungal endophyte and root herbivores of Ammophila arenaria. Basic and Applied Ecology, 8, 500-509.

Johnson, N. C., Graham, J. H., \& Smith, F. A. (1997). Functioning of mycorrhizal associations along the mutualism-parasitism continuum. New Phytologist, 135, 575-585.

Klironomos, J. N., McCune, J., \& Moutoglis, P. (2004). Species of arbuscular mycorrhizal fungi affect mycorrhizal responses to simulated herbivory. Applied Soil Ecology, 26, 133-141.

Koske, R. E., \& Gemma, J. N. (1997). Mycorrhizae and succession in plantings of beachgrass in sand dunes. American Journal of Botany, 84, 118-130.

Kowalchuk, G. A., De Souza, F. A., \& Van Veen, J. A. (2002). Community analysis of arbuscular mycorrhizal fungi associated with Ammophila arenaria in Dutch coastal sand dunes. Molecular Ecology, 11, 571-581.

Kowalchuk, G. A., Gerards, S., \& Woldendorp, J. W. (1997). Detection and characterization of fungal infections of Ammophila arenaria (marram grass) roots by denaturing gradient gel electrophoresis of specifically amplified 18S rDNA. Applied and Environmental Microbiology, 63, 3858-3865.

Little, L. R., \& Maun, M. A. (1996). The "Ammophila problem" revisited: A role for mycorrhizal fungi. Journal of Ecology, 84, 1-7.

Maherali, H., \& Klironomos, J. N. (2007). Influence of phylogeny on fungal community assembly and ecosystem functioning. Science, 316, 1746-1748.

Muyzer, G., \& Smalla, K. (1998). Application of denaturing gradient gel electrophoresis (DGGE) and temperature gradient gel electrophoresis (TGGE) in microbial ecology. Antonie van Leeuwenhoek, 73, 127-141.

Piśkiewicz, A. M., Duyts, H., Berg, M. P., Costa, S. R., \& van der Putten, W. H. (2007). Soil microorganisms control plant ectoparasitic nematodes in natural coastal foredunes. Oecologia, 152, 1432-1939.

Rodriguez-Echeverria, S., \& Freitas, H. (2006). Diversity of AMF associated with Ammophila arenaria ssp. arundinacea in Portuguese sand dunes. Mycorrhiza, 16, 543-552.

Rodriguez-Echeverria, S., Freitas, H., \& van der Putten, W.H. Genetic diversity and differentiation of Ammophila arenaria (L.) Link as revealed by ISSR markers. Journal of Coastal Research, 24(1), 122-126.

Rodriguez-Echeverria, S., Hol, W. H. G., Freitas, H., Eason, W. R., \& Cook, R. (2007). Arbuscular mycorrhizal fungi of Ammophila arenaria (L.) Link: Spore abundance and root colonisation in six locations of the European coast. European Journal of Soil Biology, 44(1), 30-36.

Roncadori, R. W. (1997). Interactions between arbuscular mycorrhizas and plant-parasitic nematodes in agro-systems. In A. C. Gange, \& V. K. Brown (Eds.), Multritrophic interactions in terrestrial systems (pp. 101-114). London: Blackwell Science.

Smith, G. S. (1987). Interactions of nematodes with mycorrhizal fungi. In J. A. Veech, \& D. W. Dickson (Eds.), Vistas on Nematology (pp. 307-312). Hyattsville, USA: Society of Nematologists, Inc.

Van der Putten, W. H., Maas, P. W. T., Van Gulik, W. J. M., \& Brinkman, H. (1990). Characterization of soil organisms involved in the degeneration of Ammophila arenaria. Soil Biology and Biochemistry, 22, 845-852.

Van der Putten, W. H., Van Dijk, C., \& Peters, B. A. M. (1993). Plant-specific soil-borne diseases contribute to succession in Foredune vegetation. Nature, 362, 53-56.

Van der Putten, W. H., Vet, L. E. M., Harvey, J. A., \& Wackers, F. L. (2001). Linking above- and below-ground multitrophic interactions of plants, herbivores, pathogens, 
and their antagonists. Trends in Ecology \& Evolution, 16, $547-554$.

Van der Stoel, C. D., \& van der Putten, W. H. (2006). Dispersal strategy of cyst nematodes (Heterodera arenaria) in the plant root zone of mobile dunes and consequences for emergence, survival and reproductive success. Applied Soil Ecology, 34, 176-183.
Wall, J. W., Skene, K. R., \& Neilson, R. (2002). Nematode community and trophic structure along a sand dune succession. Biology and Fertility of Soils, 35, 293-301.

Wardle, D. A., Bardgett, R. D., Klironomos, J. N., Setala, H., van der Putten, W. H., \& Wall, D. H. (2004). Ecological linkages between aboveground and belowground biota. Science, 304, 1629-1633.

Available online at www.sciencedirect.com 